\title{
Dimethylethylamine in mould core manufacturing: exposure, metabolism, and biological monitoring
}

\author{
T Lundh, B Ståhlbom, B Åkesson
}

\begin{abstract}
The exposure and metabolism of dimethylethylamine (DMEA) was studied in 12 mould core makers in four different foundries using the Ashland cold box technique. The mean time weighted average (TWA) full work shift DMEA exposure concentration was $3.7 \mathrm{mg} / \mathrm{m}^{3}$. Inhaled DMEA was excreted into urine as the original amine and as its metabolite dimethylethylamine-N-oxide (DMEAO). This metabolite made up a median of 87 (range 18-93) \% of the sum of DMEA and DMEAO concentrations excreted into the urine. Occupational exposure did not significantly increase the urinary excretion of dimethylamine or methylethylamine. The data indicate half lives after the end of exposure for DMEA in urine of 1.5 hours and DMEAO of three hours. The postshift summed concentration of DMEA and DMEAO in plasma and urine is a good indicator of the TWA concentration in air during the workday, and might thus be used for biological monitoring. An air concentration of $10 \mathrm{mg} / \mathrm{m}^{3}$ corresponds to a urinary excretion of the summed amount of DMEA and DMEAO of $135 \mathrm{mmol} / \mathrm{mol}$ creatinine.
\end{abstract}

Amines are common in the chemical and pharmaceutical industries. Tertiary aliphatic amines are often used as catalysts in polymer production, in the synthesis of pharmaceuticals, and as $\mathrm{pH}$ adjusters. ${ }^{1}$ Dimethylethylamine (DMEA), an aliphatic tertiary amine, is frequently used in foundries as a catalyst in the core making process. ${ }^{2}$

\footnotetext{
Department of Occupational and Environmental Medicine, University Hospital, S-221 85 Lund, Sweden

T Lundh, B Åkesson

Department of Occupational Medicine, University Hospital, S-851 85 Linköping, Sweden

B Ståhlbom
}

Tertiary amines used as catalysts are corrosive and are known to be local irritants that affect the eyes, the mucous membranes of the nose and throat, and the skin, and they may cause headache, nausea, and faintness. ${ }^{2} \mathrm{~N}$-methylmorpholine has been associated with bronchial hyperreactivity. ${ }^{3}$ The most frequently reported adverse effects, however, are visual disturbances. $^{245}$ Thus experimental exposure to DMEA $\left(40 \mathrm{mg} / \mathrm{m}^{3}\right)^{6}$ and to triethylamine (TEA; $\left.20 \mathrm{mg} / \mathrm{m}^{3}\right)^{7}$ produced foggy vision due to epithelial corneal oedema. In the occupational setting, these effects were caused by eight hour exposure concentrations (time weighted average (TWA)) of DMEA of $1-45 \mathrm{mg} / \mathrm{m}^{3}$ and TEA of $12-13 \mathrm{mg} / \mathrm{m}^{3}$. $^{8-11}$

Tertiary aliphatic amines are absorbed through the respiratory $^{12}$ and gastrointestinal ${ }^{13-15}$ tracts, and through the skin. ${ }^{16}$ The most important route of biotransformation is oxygenation of the nucleophilic nitrogen by a flavin-containing monooxygenase (FMO; Ziegler's enzyme $)^{17}$ to stable amine-Noxides. ${ }^{18}$ The amines and their amine- $\mathrm{N}$-oxides, which appear in plasma, are quantitatively excreted in urine. ${ }^{14} 15$ and B Ståhlbom, T Lundh, B Åkesson, unpublished data.

For trimethylamine (TMA) and TEA ${ }^{19}$ a substantial interindividual variation in the degree of oxygenation exists and an inherent deficiency of TMA metabolism is present in about $2 \%$ of a British population $^{20}$ (fish odour syndrome; trimethylaminuria). ${ }^{21}$

Evaluation of workers' exposure and risk by air sampling is difficult and expensive. Also, any absorption through the skin is disregarded. Thus there is a need for biological monitoring of occupational exposure to DMEA, as has been used for TEA. ${ }^{19}$ For DMEA, concentration of the amine and dimethylethylamine-N-oxide (DMEAO) in blood plasma and urine may be useful. This requires information, however, on the relation between occupational exposure and concentrations in biological index media and on metabolism, including interindividual variations and kinetics.

Experimental studies in four subjects showed that inhaled DMEA was readily absorbed and biotransformed into DMEAO (unpublished data). The 
average half life of DMEA in plasma was 1.3 hours and DMEAO 3.6 hours. DMEA was quantitatively excreted into the urine partly as the original amine, and $90 \%$ as DMEAO. The urinary excretion indicated a two phase pattern. The average half lives of DMEA in urine were 1.5 hours (first phase) and five hours (second phase). Those of DMEAO were 2.5 hours and seven hours. Further information on industrial exposure is needed.

As well as $\mathrm{N}$-oxygenation, tertiary aliphatic amines may also undergo C-oxidative dealkylation to secondary amines, ${ }^{15}$ a toxicologically important aspect, in regard to the possibility of formation of carcinogenic nitrosamines in the case of DMEA-for example, $\mathrm{N}$-nitroso-dimethylamine. It is not known whether this occurs with DMEA.

We report data here on the exposure to and metabolism of DMEA in occupationally exposed workers.

\section{Methods \\ SUBJECTS \\ The metabolism of DMEA was studied in 12 mould core workers (mean age 38, range 23-62 years; 10 men and two women) in four different foundries. Six workers were smokers. One of the workers used metformin and glibenclamide for diabetes and metoprolol for hypertension.}

\section{PROCESS}

Cores were made from a mixture of silica sand, liquid phenolic resin, and methylenediphenyl diisocyanate (MDI) in a core box machine (the Ashland cold box technique; Isocure process). The cores were cured by a few seconds of exposure to gaseous DMEA. Dry air was then blown through the core to purge any remaining DMEA. In all four foundries, the cold box machine had a standard local exhaust ventilation. Also general workroom ventilation systems were in operation. In one of the foundries, the machines were new and situated in a large production hall; the three others had older equipment in small rooms. As well as DMEA, the workers were exposed to 1,1,1-trichloroethane (TCE), waxes, and MDI.

\section{AIR SAMPLES}

The TWA exposure to DMEA was measured in each worker, in his or her personal breathing zone by absorption in impinger flasks during the full work shift (eight hours) divided into about one hour sampling periods. ${ }^{22}$

\section{BLOOD SAMPLING}

Blood samples $(20 \mathrm{ml})$ were collected by venepuncture before the start of exposure, and immediately after the end of exposure. The samples were collected (in a room free from exposure) in heparinised tubes.
After 30 minutes the samples were centrifuged ( $1500 \mathrm{~g}$ for 15 minutes), $2 \mathrm{ml}$ plasma was acidified with $0.5 \mathrm{ml} 1 \mathrm{M}$ hydrochloric acid $(\mathrm{HCl} ; 37 \%$; Merck pa, Darmstadt, Germany) and stored at $4^{\circ} \mathrm{C}$ until analysis.

\section{URINE SAMPLING}

In all workers, urine samples were collected for 24 hours during two periods before the start of exposure (night and am before the start of work), four two hour periods during exposure, and six periods after the end of exposure (four two hour periods, overnight, and am before the start of work). The urine samples were acidified with concentrated $\mathrm{HCl}(2 \mathrm{ml}$ per $100 \mathrm{ml}$ urine), and refrigerated $\left(4^{\circ} \mathrm{C}\right)$ until analysis (within three months).

\section{ANALYSES}

The analyses of DMEA and DMEAO in air samples, plasma, and urine were performed by gas liquid chromatography. ${ }^{22}$ There was no interference from the other compounds present in workroom air, blood, or urine.

The acidity of urine was determined by strip test (Acilit pH 0-6, 5-10, Merck, Germany), and the creatinine concentrations in urine were determined according to a modified kinetic Jaffé method..$^{23}$ The precision, as determined from duplicate analyses, was $5 \%$.

\section{Results}

\section{EXPOSURE}

The mean TWA full work shift DMEA exposure concentration in the foundries studied was $3 \cdot 7$ (range $0.5-14) \mathrm{mg} / \mathrm{m}^{3}$. The concentrations of 96 one hour sampling periods ranged from $0 \cdot 1$ to $22 \mathrm{mg} / \mathrm{m}^{3}$ with no systematic trend over shifts. Lower concentrations were recorded in the foundry with new machines in a large workroom (eight hour TWA 1.3, range $0.5-2.4 \mathrm{mg} / \mathrm{m}^{3}$ ) and higher concentrations in the three with old equipment in small rooms (eight hour TWA $5 \cdot 4$, range $\left.2 \cdot 5-14 \mathrm{mg} / \mathrm{m}^{3}\right)$. No DMEAO was detected in air samples $\left(<0.002 \mathrm{mg} / \mathrm{m}^{3}\right)$.

\section{CONCENTRATIONS OF DMEA AND DMEAO IN PLASMA}

Before exposure, the average concentrations of DMEA and DMEAO in plasma were below the detection limits $(0.04 \mu \mathrm{mol} / 1$ for DMEA and 0.07 (range $<0.04-0.20) \mu \mathrm{mol} / 1$ for DMEAO). Postshift the concentrations were 0.21 (range $<0.04-1.0$ $\mu \mathrm{mol} / 1$ for DMEA) and 1.8 (range $0.3-7 \cdot 2$ ) $\mu \mathrm{mol} / 1$ for DMEAO. These differences are statistically significant $(p<0.001$; Wilcoxon's matched pairs ranked sign test). The mean DMEAO fraction of the summed amounts of DMEA and DMEAO in postshift plasma was $91 \%$ (range $74-100 \%$ ). 
URINARY EXCRETION OF DMEA AND DMEAO

DMEA was readily absorbed and eliminated into urine as DMEA and DMEAO. After start of exposure, the DMEA and DMEAO excretion in urine increased until the end of exposure, and then decreased again (fig 1). The mean DMEAO fraction in the urine was $81 \%$ (range 18-93\%). In the two women (sisters) studied, DMEAO fractions were considerably lower (18\% and $63 \%)$, compared with the men (84-93\%).

In the 12 workers studied, there was no difference in dimethylamine (DMA) concentrations in samples before (mean 16, range $8-19 \mathrm{mmol} / \mathrm{mol}$ creatine) or after (mean 13, range $8-19 \mathrm{mmol} / \mathrm{mol}$ creatine; two hours postshift) exposure. No methylethylamine (MEA) could be found in the urine sampled.

Half lives of DMEA in urine after the end of exposure had a mean of 1.5 hours (range $1 \cdot 1-2 \cdot 2$ ). The average half life of DMEAO in urine was 2.9 hours (range 2.6-3.9).

\section{PLASMA V URINARY CONCENTRATIONS OF DMEA AND DMEAO}

A close correlation was found between summed concentrations of DMEA and DMEAO in plasma (postshift) and in urine (samples obtained during two hours postshift) (Spearman's rank correlation; $r_{s}=0.96, p=0.002$; fig 2).

\section{EXPOSURE V PLASMA AND URINARY CONCENTRATIONS} OF DMEA AND DMEAO

A close association was found between the air concentrations of DMEA on the one hand, and the postshift concentrations of the summed DMEA and DMEAO in plasma $\left(r_{s}=0.92, p=0.002\right.$; fig 3$)$ and the urinary excretion of the summed DMEA and

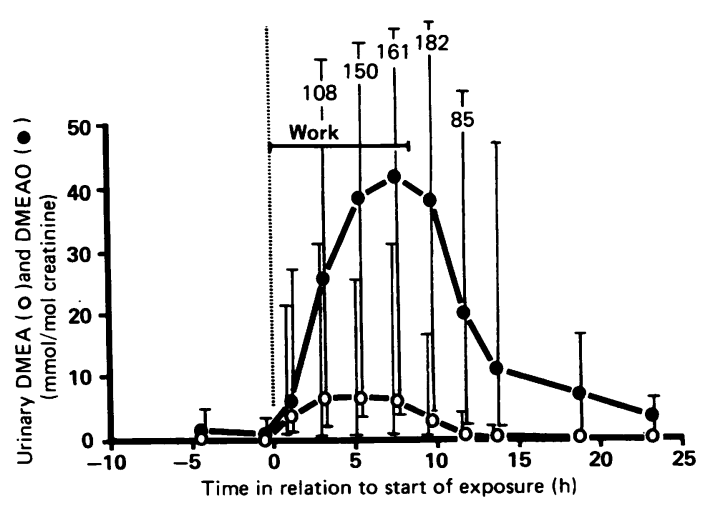

Figure 1 Mean urinary concentrations of DMEA and $D M E A O$ in 12 core making workers before, during, and after exposure to DMEA. The range between individual subjects is shown, DMEA to the left, DMEAO to the right.

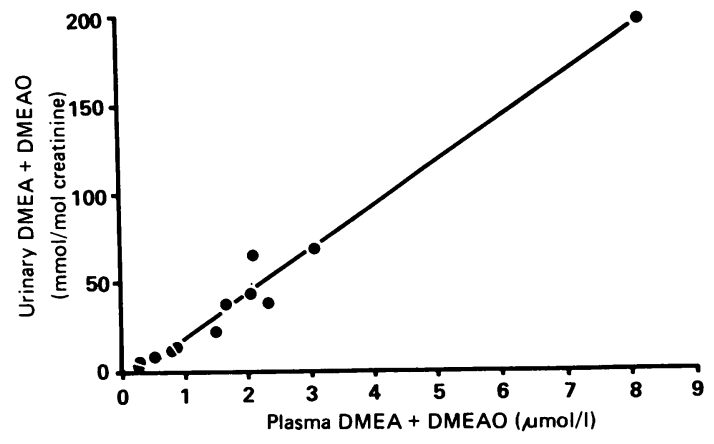

Figure 2 Relation between plasma (postshift) and urinary excretion (samples obtained during two hours postshift) of the summed DMEA and DMEAO concentrations in 12 core making workers exposed to DMEA. The regression line is shown $\left(Y=25 X-6 ; r_{s}=0.96\right)$.

DMEAO during two hours postshift $\left(r_{s}=0.91\right.$, $p=0.003$; fig 4 ), on the other.

\section{Discussion}

Exposure to DMEA at a concentration of 1-14 $\mathrm{mg} / \mathrm{m}^{3}$ in the present workers was far below official occupational standards (Denmark and Germany, $\left.75 \mathrm{mg} / \mathrm{m}^{3}\right){ }^{24} 25$ Exposure to only $6-10 \mathrm{mg} / \mathrm{m}^{3}$ has, however, caused visual disturbances in the workers. ${ }^{9}$ Also, discrete ocular changes have been recorded at an exposure of about $10 \mathrm{mg} / \mathrm{m}^{3}$.

In most subjects, the urinary DMEAO fraction was about $90 \%$. This is in accordance with findings from experimental studies (unpublished data). The fraction is considerably larger than that of TEA ${ }^{12}$ and somewhat lower than that of TMA. ${ }^{14}$

Two workers (sisters) had a considerably lower DMEAO fraction (18 and $63 \%$ ). This was probably due to less oxygenation of DMEA to DMEAO, and not to a difference between men (84-93\%) and women, as the TMAO fraction (TMAO as a percentage of summed TMA and TMAO) in urine, which occurred as a result of dietary intake. of TMA precursors $^{14}$ in these two women, was also lower (24 and $92 \%$ ), than the expected $95 \%$ or greater. ${ }^{14}$ Thus the low fractions found in the sisters may be an inherited deficiency in oxygenation of tertiary aliphatic amines to amine-N-oxides, similar to that found in trimethylaminuria. ${ }^{21}$

The excretion patterns for DMEA and DMEAO found and the half lives for the concentrations in urine agree with those recorded in experimentally exposed male volunteers (unpublished data). The half life for DMEAO in the urine should be somewhat longer than the half life of the compound in the 


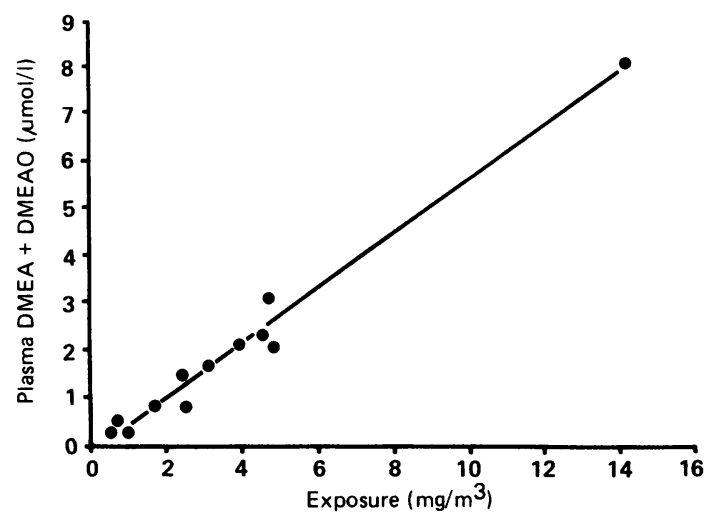

Figure 3 Relation between DMEA exposure (eight hour time weighted air concentrations) and concentrations of summed DMEA and DMEAO in plasma (postshift) in 12 core making workers. The regression line is shown $\left(Y=0.59 X-0.17 ; r_{s}=0.92\right)$.

body, as there was a continuous formation of DMEAO during the study. The excretion was rather slow and was not fully complete even by the next morning. Thus there should be a slight tendency of accumulation during the work week. Over the weekend, the body should be completely cleared of the agents. There seemed to be a two phase elimination pattern of DMEA and DMEAO in urine, although the observation time, between the end of the exposure one day and the onset of the exposure the next day, was too short for an accurate evaluation. The finding is in accordance, however, with those from an experimental study (unpublished data).

Out of the many other pollutants present in the air of the foundries, the possibility of metabolic interaction between TCE and DMEA should be considered.

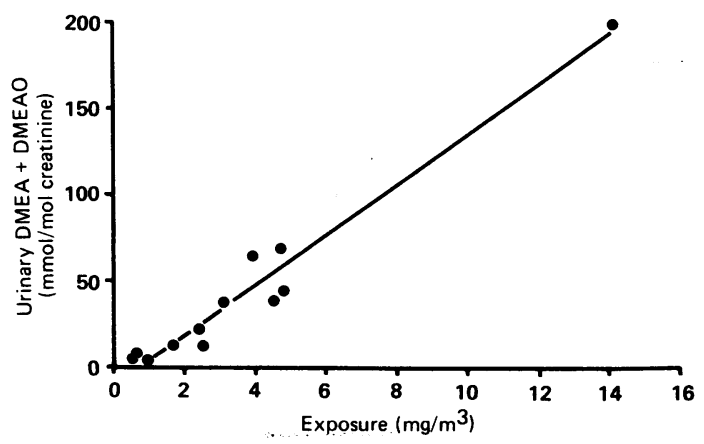

Figure 4 Relation between DMEA exposure (eight hour time weighted air concentrations) and urinary excretion ( samples obtained during two hours postshift) of summed $D M E A$ and DMEAO in 12 core making workers. The regression line is shown $\left(Y=15 X-10 ; r_{s}=0.91\right)$.
The TCE, however, is biotransformed by a cytochrome $\mathrm{P}-450$ system, and only to a minor extent, ${ }^{26}$ whereas probably the major part of DMEA is biotransformed differently by a flavin-containing monoxygenase. ${ }^{17}$ Thus an interaction of importance seems unlikely.

There was no indication of any significant demethylation of DMEA, as MEA was not detected in the urine. As to a possible de-ethylation into DMA, considerable DMA concentrations were found both before and after exposure. The main part of this DMA had probably been formed endogenously from dietary sources. ${ }^{20}$ These amounts of DMA are so large, that a minor degree of de-ethylation of DMEA would be unidentified. It does not seem likely, however, that occupational exposure to DMEA would significantly increase the amount of DMA available for formation of nitrosamines. The present data accord with experimental exposure to DMEA (unpublished data), and with observations on other tertiary aliphatic amines. ${ }^{12}{ }^{14}$ In accordance with DMA, ethylamine, probably from foods, occurred in urine samples irrespective of exposure. Thus a minor formation from the DMEA could not be excluded. Methylamine was not studied, as the sample handling and analysis were unsuitable for its determination. The presence of $\mathrm{N}$-nitroso-amines in air, derived from impurities of the catalysts or formed from decomposition of DMEA in the process, ${ }^{27}$ was not studied.

Theoretically, the DMEA concentration in plasma and the corresponding urinary excretion would be useful biological indices for monitoring of uptake, but the inter-individual variation of DMEA oxygenated into DMEAO was large (7-82\%). Probably mainly as a result of this, neither DMEA nor DMEAO individually displayed a good correlation with DMEA concentrations in air. Thus the summed DMEA and DMEAO must be used for biological monitoring. This sum in plasma and urine displayed a close association with the air concentration. This indicates that skin absorption is not a main route of uptake, at least not in the occupational setting studied.

Both plasma and urine may be used for biological monitoring; as urine contains more than 100-fold higher concentrations, urine analyses would be simpler and more informative.

Twenty four hour urine samples are better than postshift samples, but 24 hour sampling presents practical difficulties. Instead, postshift concentrations should be used for monitoring; the excreted amounts of the summed DMEA and DMEAO in the two hour postshift samples showed a good correlation with the DMEA concentrations in air. The urinary concentrations should be corrected for the concentration of creatinine.

These data indicate that a TWA exposure of 
$10 \mathrm{mg} / \mathrm{m}^{3}$ corresponds to a concentration of the summed DMEA and DMEAO in urine of 135 $\mathrm{mmol} / \mathrm{mol}$ creatinine and in plasma of $5.7 \mu \mathrm{mol} / 1$, which are plausible as biological exposure limits. Although we have no data on heavy occupational exposure, by linear extrapolation of our results in combination with earlier observations of up to $50 \mathrm{mg} / \mathrm{m}^{3}$, an exposure of $40 \mathrm{mg} / \mathrm{m}^{3}$ would correspond to a urinary concentration of about 570 $\mathrm{mmol} / \mathrm{mol}$ creatinine and a plasma concentration of about $23 \mu \mathrm{mol} / \mathrm{l}$ and $100 \mathrm{mg} / \mathrm{m}^{3}$ to about 1.4 $\mathrm{mol} / \mathrm{mol}$ creatinine and $58 \mu \mathrm{mol} / \mathrm{l}$. This applies to light to moderate physical work; heavy work might result in concentrations several times higher.

Mrs Else-Britt Gustavsson and Mrs Karin Paulsson supplied excellent technical help. The study was supported by a grant (88-0161) from the Swedish Work Environment Fund.

Requests for reprints to: Bengt Åkesson, Department of Occupational and Environmental Medicine, University Hospital, S-22185 Lund, Sweden.

1 Clayton GD, Clayton FE. Patty's industrial hygiene and toxicology. 3rd ed. Vol IIb Toxicology of aliphatic and alicyclic amines. New York: Wiley Interscience, 1982:3135-73.

2 Albrecht WN, Stephenson RL. Health hazards of tertiary amine catalysts. Scand J Work Environ Health 1988;14:209-19.

3 Belin L, Wass U, Audunsson G, Mathiasson L. Amines: possible causative agents in the development of bronchial hyperreactivity in workers manufacturing polyurethanes from isocyanates. Br J Ind Med 1983;40:251-7.

4 Brieger $\mathrm{H}$, Hodes WA. Toxic effects of exposure to vapors of aliphatic amines. Archives of Industrial Hygiene and Occupational Medicine 1951;3;:287-91.

5 Dernehl CU. Health hazards associated with polyurethane foams. J Occup Med 1966;7:59-62.

6 Ståhlbom B, Lundh T, Floren I, Ákesson B. Visual disturbances in man as a result of expcrimental and occupational exposure to dimethylethylamine. $\mathrm{Br} J$ Ind Med 1991;48:26-9.

7 Ákesson B, Florén I, Skerfving S. Visual disturbances after experimental human exposure to triethylamine. $\mathrm{Br} J$ Ind $\mathrm{Med}$ 1985;42:848-50.

8 Blome H, Hennig M. Messung ausgewählter aliphatischer und aromatischer Amine in der Luft von Arbeitbereichen. StaubReinhalt Luft 1984;44:27-32.

9 Schmittner $\mathrm{H}$. Arbeitsmedizinische und arbeitshygienische Untersuchungen beim Cold-Box- und Maskenformverfahren. Giesserei 1984;71:895-902.
10 Stephenson RL, Albrecht WN. Health hazard evaluation 85-482-1730. Cincinnati, Ohio: National Institute for Occupational Safety and Health, 1986.

11 Akesson B, Bengtsson M, Florén I. Visual disturbances by industrial triethylamine exposure. Int Arch Occup Environ Health 1986;57:297-302.

12 Akesson B, Skerfving S, Mathiasson L. Experimental study on the metabolism of triethylamine in man. $B r J$ Ind Med $1988 ; 45: 262-8$

13 Lintzel W. Untersuchungen über Trimethylammonium-basen. III. Mitteilung: Trimethylammoniumbasen im menschlichen Harn. Biochem Z 1934;273:243-61.

14 Al-Waiz M, Mitchell SC, Idle JR, Smith RL. The metabolism of ${ }^{14} \mathrm{C}$-labelled trimethylamine and its $\mathrm{N}$-oxide in man. Xenobiotica 1987;17:551-8.

15 Akesson B, Vinge E, Skerfving S. Pharmacokinetics of triethylamine and triethylamine- $\mathrm{N}$-oxide in man. Toxicol Appl Pharmacol 1989;100:529-38.

16 Scott TS, Munn A, Smagghe G. Amines, aromatic. In: Parmeggiani L, ed. Encyclopaedia of occupational health and safety, $\mathrm{Vol}$ 1. Geneva: BIT, 1983:141-7.

17 Ziegler DM. Metabolic Oxygenation of Organic Nitrogen and Sulfur Compounds. In: Mitchell JR, Horning MG, eds. Drug Metabolism and Drug Toxicity. New York: Raven Press, 1984: 33-53

18 Bickel MH. The pharmacology and biochemistry of $\mathrm{N}$-oxides. Pharmacol Rev 1969;21:325-55.

19 Akesson B, Skerfving S, Stählbom B, Lundh T. Metabolism of triethylamine in polyurethane foam manufacturing workers Am J Ind Med 1989;16:255-65.

20 Ayesh R, Smith RL. Genetic polymorphism of trimethylamine N-oxidation. Pharmacol Ther 1990;45:387-401.

21 Al-Waiz M, Ayesh R, Mitchell SC, Idle JR, Smith RL. Trimethylaminuria (fish-odour syndrome): an inborn error of oxidative metabolism. Lancet 1987;i:634-5.

22 Lundh T, Stahlbom B, Akesson B. Methods for the determination of dimethylethylamine and dimethylethylamine- $\mathrm{N}$-oxide in air, plasma, and urine samples. Int J Environ Anal Chem (in press).

23 Lustgarten JA, Wenk RE. Simple, rapid kinetic method for serum creatinine measurement. Clin Chem 1972;18:1419-22. (Modified by Masson P, Department of Clinical Chemistry, University Hospital, Lund. Personal communication.)

24 Arbejdstilsynets anvisning $\mathrm{Nr}$ 3.1.0.2. Groensevordier for stoffer og materialer. Køpenhavn, Danmark: Direktoratet for Arbejdstilsynet, 1988:17.

25 Mitteilung XXV der Senatskommission zur Prüfung gesundheitsschädlicher Arbeitsstoffe. Maximale Arbeitsplatzkonzentrationen und Biologische Arbeitsstofftoleranzwerte. Deutsche Forschungsgemeinschaft, ed. Weinheim: VCH Verlagsgesellschaft, 1989:38.

26 Imbriani M, Ghittori S, Pezzagno G, Huang J, Capodaglio J. $1,1,1$-Trichloroethane (methyl chloroform) in urine as biological index of exposure. Am J Ind Med 1988;13:211-22.

27 Ducos P, Gaudin R, Maire C, Navelle T, Bouchikhi B, Derby G. Occupational exposure to volatile nitrosamines in foundries using the "Ashland" core-making process. Environ Res 1988;47:72-8.

Accepted 3 September 1990 